\title{
Prenatal Exposure to Sodium Arsenite Alters Placental Glucose 1, 3, and 4 Transporters in Balb/c Mice
}

\author{
Daniela Sarahí Gutiérrez-Torres, ${ }^{1}$ Carmen González-Horta, ${ }^{1}$ \\ Luz María Del Razo, ${ }^{2}$ Rocío Infante-Ramírez, ${ }^{1}$ Ernesto Ramos-Martínez, ${ }^{3}$ \\ Margarita Levario-Carrillo, ${ }^{4}$ and Blanca Sánchez-Ramírez ${ }^{1}$
${ }^{1}$ Programa de Maestría en Ciencias en Biotecnología, Facultad de Ciencias Químicas, Universidad Autónoma de Chihuahua, Circuito No. 1 Nuevo Campus Universitario, 31125 Chihuahua, CHIH, Mexico
${ }^{2}$ Departamento de Toxicología, Centro de Investigación y Estudios Avanzados del Instituto Politécnico Nacional (CINVESTAV), Avenida Instituto Politécnico Nacional 2508, 07360 Mexico, DF, Mexico
${ }^{3}$ Departamento de Anatomía Patológica del Hospital CIMA, Avenida Hacienda del Valle No. 7120, 31217 Chihuahua, CHIH, Mexico
${ }^{4}$ Laboratorio de Embriología, Facultad de Medicina, Universidad Autónoma de Chihuahua, Nuevo Campus Universitario, 31125 Chihuahua, CHIH, Mexico

Correspondence should be addressed to Blanca Sánchez-Ramírez; bsanche@uach.mx

Received 28 November 2014; Accepted 17 April 2015

Academic Editor: Petros Gikas

Copyright @ 2015 Daniela Sarahí Gutiérrez-Torres et al. This is an open access article distributed under the Creative Commons Attribution License, which permits unrestricted use, distribution, and reproduction in any medium, provided the original work is properly cited.

\begin{abstract}
Inorganic arsenic (iAs) exposure induces a decrease in glucose type 4 transporter (GLUT4) expression on the adipocyte membrane, which may be related to premature births and low birth weight infants in women exposed to iAs at reproductive age. The aim of this study was to analyze the effect of sodium arsenite $\left(\mathrm{NaAsO}_{2}\right)$ exposure on GLUT1, GLUT3, and GLUT4 protein expression and on placental morphology. Female Balb/c mice $(n=15)$ were exposed to 0,12 , and $20 \mathrm{ppm}$ of $\mathrm{NaAsO}_{2}$ in drinking water from 8th to 18th day of gestation. Morphological changes and GLUT1, GLUT3, and GLUT4 expression were evaluated in placentas by immunohistochemical and image analysis and correlated with iAs and arsenical species concentration, which were quantified by atomic absorption spectroscopy. $\mathrm{NaAsO}_{2}$ exposure induced a significant decrease in fetal and placental weight $(P<0.01)$ and increases in infarctions and vascular congestion. Whereas GLUT1 expression was unchanged in placentas from exposed group, GLUT3 expression was found increased. In contrast, GLUT4 expression was significantly lower $(P<0.05)$ in placentas from females exposed to $12 \mathrm{ppm}$. The decrease in placental GLUT4 expression might affect the provision of adequate fetal nutrition and explain the low fetal weight observed in the exposed groups.
\end{abstract}

\section{Introduction}

Inorganic arsenic (iAs) is a ubiquitous element and its toxicity has been demonstrated both in humans [1-5] and in experimental models [6]. Groundwater concentration of As has been documented in the literature, which reveals a very large range from less than 0.001 to $5 \mathrm{ppm}$ covering natural As contamination found in more than 70 countries $[7,8]$. Chronic exposure to iAs through contaminated water has been associated with reproductive disorders. Exposure has caused spontaneous abortions, stillbirths, premature births, and low birth weight infants in women of reproductive age [9-12]. The mechanisms by which iAs negatively affects reproductive health are, however, poorly understood. During pregnancy, the placenta maintains the fetal development, ensuring an adequate supply of nutrients and the removal of waste products from the fetal circulation to maternal circulation $[13,14]$. Transplacental transport of nutrients is carried out by various proteins such as glucose transporters (GLUT) located in the cell membranes of maternal and fetal structures $[15,16]$. To date, there are reports of the expression of the isoforms GLUT1, GLUT3, and GLUT4 in placental tissue from both humans and mice and suggestions for the function of each isoform [17]. GLUT1 has been related to 
the transfer of glucose from maternal circulation to the placenta. In contrast, GLUT3 seems to function in transferring glucose from the placenta to fetal blood, and GLUT4 contributes to meeting the metabolic needs of the placenta $[18,19]$. Although the placenta is highly selective when preventing the passage of toxic substances to the fetus, a relationship between the levels of iAs and its metabolites found in placenta and umbilical cord blood has been reported, indicating a considerable transfer of As from the mother to the developing fetus [20]. Transplacental exposure to arsenicals may cause alterations in fetal development that leave the individual predisposed to diseases in adulthood such as atherosclerosis, type 2 diabetes mellitus and metabolic syndrome, cardiovascular disease, neuropathy, and cancer [6, 21-24]. Moreover, chronic iAs exposure has a deleterious effect on peripheral glucoregulation. It can decrease both expression and secretion of insulin in the body [25], the translocation of GLUT4 toward the surface of the membrane in adipose tissue cells [26], and glucose uptake so that glucose levels are increased in peripheral blood.

iAs is extensively metabolized by humans and many other species to yield two major methylated metabolites, methyl As (MAs) and dimethyl As (DMAs) [27]. Because the action of iAs as a toxin is fundamentally influenced by its metabolism, placental patterns of iAs and its metabolites are relevant to assessing the risk of toxicity by this metalloid.

The aim of this study was to analyze the expression of GLUT1, GLUT3, and GLUT4 transporters in placentas from mice exposed to 0,12 , and $20 \mathrm{ppm}$ of sodium arsenite $\left(\mathrm{NaAsO}_{2}\right)$ from the 8 th to 18 th day of gestation. Additionally, we conducted a histopathology study in the three zones of the placenta (decidua basalis, junction zone, and labyrinth) to describe the lesions and their relationship with iAsexposure.

\section{Materials and Methods}

We obtained acetone, ethanol, methanol, potassium chloride, potassium phosphate monobasic, sodium chloride, sodium hydroxide, sodium phosphate dibasic, disodium hydrogen arsenate heptahydrate, phosphoric acid (Ultrex II), and xylene from JT Baker (Estado de México, México). Tris$\mathrm{HCl}$ was purchased from Gibco BRL (Rockville, Maryland, USA) and monomethylarsenate from Supelco (St. Louis, Missouri, USA). 3-Aminopropyl triethoxysilane, hydrogen peroxide, paraformaldehyde, polyoxyethylene sorbitan monolaurate (Tween 20), dimethylarsonic acid, sodium arsenite $\left(\mathrm{NaAsO}_{2}\right)$, and sodium borohydride were purchased from Sigma-Aldrich (St. Louis, Missouri, USA). Entellan mounting resin and sodium hydroxide were obtained from Merck (Darmstadt, Germany). For the immunohistochemistry (IHC) analysis, polyclonal anti-human GLUT1, GLUT3, and GLUT4 antibodies were purchased from Santa Cruz Biotechnology, Inc. (Santa Cruz, California, USA). A Histostain-plus kit and hematoxylin were obtained from Zymed Lab., Inc. (San Francisco, California, USA). Mice were fed pellets of Mouse Diet 5015 fish meal free from LabDiet, Purina Mills, Inc. (Richmond, Indiana, USA).
2.1. Animals and Treatment Conditions. Briefly, Balb/c adult female mice with a body weight of $20 \mathrm{~g}(n=15)$ were obtained from the Bioterium of the Faculty of Chemical Sciences (Autonomous University of Chihuahua). The Institutional Animal Care and Use Committee approved all animal procedures, in compliance with the Mexican Official Technical specifications for the production, care, and use of laboratory animals [28]. Animals were randomly assigned to one of three groups and treated with 0,12 , or 20 ppm of $\mathrm{NaAsO}_{2}$ (concentration of the salt) dissolved in deionized water. $\mathrm{NaAsO}_{2}$ concentrations were selected according to the lowest observed adverse effect level (LOAEL) of $5 \mathrm{ppm}$, which had a slight decrease in the median life span and no effect on growth [29]. The estrous cycle was monitored by vaginal examination; females in estrous phase were mated with males $(5: 1)$ for a period of $48 \mathrm{hr}$. The following day was considered to be day 1 of gestation. Females were observed daily during and after exposure, and body weight and water consumption were also recorded. On the 8th day of gestation, the pregnant females began to receive the treatment orally ad libitum until the 18th gestation day. The control group ( $0 \mathrm{ppm})$ was given only deionized water. At the end of treatment, the animals were euthanized by asphyxiation; the placentas and fetuses were dissected and weighed. Each placenta was divided in two, one part was fixed in $3.7 \%$ phosphate-buffered formalin, and embedded in paraffin, and another part was snap-frozen in liquid nitrogen until determination of arsenical species.

2.2. Histopathology Study. Paraffin sections ( $4 \mu \mathrm{m}$ thick) were obtained and stained with hematoxylin-eosin (H\&E). Morphological alterations were evaluated in the three main areas of the placenta (decidua basalis, junction zone, and labyrinth) by optical microscopy (10x and 60x). The analysis of the effects of treatment consisted of recording fibrosis, hemorrhage, and infarcts for the decidua zone; documenting alterations in phagocytosis or abnormal nuclei of cells in the junction zone, and observing vascular congestion and infarcts in the labyrinth zone. The morphological alterations were included in a binary database; qualitative variables were transformed into quantitative data by assigning the number " 1 " if the alteration was present and the number " 0 " for the absence of morphological alterations. These data were captured in a spreadsheet, and the percentages of morphologic alterations found in each group were calculated.

2.3. Immunohistochemical Analysis (IHC). The IHC technique was carried out according to the protocol implemented and described by our research group [30, 31] with the following modifications: after blocking (PBS pH 7.4, containing $10 \%$ nonfat milk), the slides were incubated separately for $1 \mathrm{hr}$ at $37^{\circ} \mathrm{C}$ with the corresponding polyclonal goat anti-human antiserum GLUT1, GLUT3, or GLUT4 (1:750 dilution in PBS at $\mathrm{pH} 7.4$, containing $1 \%$ non-fat milk). The slides were washed and exposed to the secondary (affinity-purified biotinylated rabbit anti-goat IgG) antibody for $1 \mathrm{hr}$ at room temperature. The signal was detected using avidin-peroxidase and freshly prepared diaminobenzidine substrate. Stained slides were dehydrated for permanent cover slipping with 
TABLE 1: Reproductive parameters in animals according to the $\mathrm{NaAsO}_{2}$ concentration in water.

\begin{tabular}{|c|c|c|c|}
\hline \multirow[b]{2}{*}{ Treated group } & \multicolumn{3}{|c|}{ Concentration of $\mathrm{NaAsO}_{2}$ in water (ppm) } \\
\hline & $\begin{array}{c}0 \\
(n=5) \\
\bar{X} \pm \mathrm{SD}\end{array}$ & $\begin{array}{c}12 \\
(n=5) \\
\bar{X} \pm \mathrm{SD}\end{array}$ & $\begin{array}{c}20 \\
(n=5) \\
\bar{X} \pm \mathrm{SD}\end{array}$ \\
\hline Increase in body weight $(\mathrm{g})^{\mathrm{a}}$ & $15.36 \pm 4.05$ & $7.18 \pm 6.02$ & $7.62 \pm 5.76$ \\
\hline Maternal weight (g) & $42.62 \pm 3.55$ & $33.8 \pm 7.28$ & $34.58 \pm 6.69$ \\
\hline Placental weight (g) & $0.169 \pm 0.02^{\mathrm{a}}$ & $0.154 \pm 0.02^{\mathrm{a}}$ & $0.147 \pm 0.02^{\mathrm{b}}$ \\
\hline Fetal weight $(\mathrm{g})$ & $0.651 \pm 0.09^{\mathrm{a}}$ & $0.611 \pm 0.10^{b}$ & $0.528 \pm 0.10^{\mathrm{b}}$ \\
\hline Number of viable fetuses/litter & $7.6 \pm 3.04$ & $7.8 \pm 3.5$ & $9.2 \pm 2.04$ \\
\hline Number of nonviable fetuses/litter & $0.2 \pm 0.44^{\mathrm{a}}$ & $1.8 \pm 1.09^{\mathrm{b}}$ & $1.2 \pm 0.83^{\mathrm{a}}$ \\
\hline
\end{tabular}

$\bar{X} \pm$ SD, mean \pm s.d. of each group; $n=$ number of females in group.

Different superscript indicate statistical difference $P<0.01$, by Bonferroni post hoc test.

Entellan resin. To prevent variability, all of the samples were processed on the same day. Paraffin sections of heart and testis from an unexposed rat were used as controls for heterologous recognition of the GLUT1 and GLUT4 transporters and GLUT3 transporter, respectively. Negative controls were obtained by omitting the primary antibody. For immune localization, slides for each GLUT transporter were contrasted with hematoxylin for $10 \mathrm{~min}$ before dehydration.

2.4. Image Analysis of GLUT1, GLUT3, and GLUT4 Expression. The level of GLUT1, GLUT3, and GLUT4 expression was obtained by optical density as measured in a BX41 Olympus microscope (Olympus Optical Co., Ltd., Mexico) equipped with a Pixera-CCD camera and analyzed with the IMAGE proplus 4.1 software (Media Cibernetics, Silver Spring, Maryland, USA) [30, 31]. Five representative microphotographs of the labyrinth were taken from each placenta at $60 \mathrm{x}$ and six measures of optical density (each with a perimeter of $5 \mu \mathrm{m}$ ) were performed for each sample $(n=300)$. After calibrating the microscope, measurements were made with an individual pixel resolution of 175 grey levels. All determinations were made on the same day to reduce calibration or lighting errors. The samples used for image analysis were not counterstained in order to avoid the background signal for hematoxylin.

2.5. Determination of Arsenical Species in Placental Tissue. Quantification of arsenical species (iAs, MAs, and DMAs) was performed by hydride generation-cryotrapping-atomic absorption spectrometry (HG-CT-AAS) [32]. Briefly, the placental tissue was homogenized in deionized water $(2.25 \mathrm{~mL}$ of water per $0.3 \mathrm{~g}$ of tissue) using a pestle homogenizer. The homogenate was placed into a conical tube and $3 \mathrm{~mL}$ of $2 \mathrm{M}$ phosphoric acid (Ultrex II) was added. The tubes were heated at $95^{\circ} \mathrm{C}$ for $1.5 \mathrm{hr}$ using a thermoblock and stirred every $15 \mathrm{~min}$ with a vortex until the sample disintegrated. Once digested, the samples were cooled to room temperature and neutralized by adding $700 \mu \mathrm{L}$ of $10.9 \mathrm{M}$ sodium hydroxide. The final cysteine concentration was adjusted to $2 \%$ using a $40 \%$ cysteine solution. After $70 \mathrm{~min}$, the level of arsenical species was determined by HG-CT-AAS [32]. Total arsenic (tAs) value was calculated as the sum of the iAs, MAs, and
DMAs contents in the placenta. The relative percentages of iAs, MAs, and DMAs in placenta were calculated so that the sum of the arsenicals constituted $100 \%$.

2.6. Statistical Analysis. The gestational parameters were analyzed as quantitative variables using an ANOVA test; differences between groups were considered significant when $P \leq 0.01$ by Bonferroni post hoc test. The histopathological changes in placental morphology were treated as outcome variables and were analyzed by a Chi square test. An ANOVA with a Bonferroni multiple comparisons post-test was used to evaluate group-specific differences in the placental distribution for tAs and individual metabolite data. Quantitative data are presented as the means \pm standard deviation. Data analyses were carried out with the STATA 9.0 program for Windows (Stata Statistical Software, Release 9.0, Stata Corporation, College Station, Texas, USA).

\section{Results}

3.1. Gain of Maternal, Fetal, and Placental Weight. In total, 15 females were included in the study. One hundred twenty five placentas and fetuses were obtained; 39 placentas belong to the group that was not exposed to iAs, and 86 belonged to the iAs-exposed groups. The characteristics of females and products are shown in Table 1. No significant differences were detected in the maternal weight gain or in maternal weight at term between the groups exposed to $\mathrm{NaAsO}_{2}$ and the nonexposed females $(P>0.05)$. However, maternal weight at term for females from exposed groups was lower than that of nonexposed females. Otherwise, placental weight was significantly decreased in the group exposed to $20 \mathrm{ppm}$ $\mathrm{NaAsO}_{2}(P<0.01)$. In case of fetal weight, a significant decrease was observed in exposed group compared with nonexposed $(P<0.01)$. No difference, in fetal weight, was detected between exposed groups. A significant increase in the number of nonviable fetuses was observed in the group exposed to $12 \mathrm{ppm}$ compared with the nonexposed group $(P<0.01)$.

3.2. Morphological Alterations in Placental Tissue. The morphological analysis of placentas from nonexposed females 
TABLE 2: Histological findings in mice placentas according to the $\mathrm{NaAsO}_{2}$ concentration.

\begin{tabular}{|c|c|c|c|}
\hline & \multicolumn{3}{|c|}{ Concentration of $\mathrm{NaAsO}_{2}$ in water (ppm) } \\
\hline & 0 & 12 & 20 \\
\hline & $n(\%)$ & $n(\%)$ & $n(\%)$ \\
\hline \multicolumn{4}{|l|}{ Decidua } \\
\hline Fibrosis & $41(100)$ & $25(100)$ & $46(100)$ \\
\hline Hemorrhage & $29(71)$ & $18(72)$ & $40(87)$ \\
\hline \multicolumn{4}{|l|}{ Junction zone } \\
\hline Infarct & $24(58)$ & $20(80)$ & $39(85)^{*}$ \\
\hline Phagocytosis in TGC & $41(100)$ & $25(100)$ & $46(100)$ \\
\hline Abnormal nucleus & 0 & 0 & 0 \\
\hline Degenerative GC & $41(100)$ & $25(100)$ & $46(100)$ \\
\hline \multicolumn{4}{|l|}{ Labyrinth } \\
\hline Infarct & 0 & 0 & $1(2.2)$ \\
\hline Vascular congestion & $27(66)$ & $25(100)^{*}$ & $45(98)^{*}$ \\
\hline
\end{tabular}

showed normal cellular architecture (Figure 1(a)); no microscopic alterations were observed in the labyrinth (Figure 1(d)). However, fibrosis and hemorrhagic processes were observed in the decidua basalis area. In placentas from $\mathrm{NaAsO}_{2}$ exposed females, it was common to detect hemorrhagic zones (Figure 1(c)) and infarct lesions in decidua basalis, where the cells were replaced by fibrinoid material (Figure 1(b)). In the labyrinth zone, vascular congestion was evident (Figure 1(e)) in placentas from females in the groups exposed to any concentration of $\mathrm{NaAsO}_{2}$. Microinfarction with cellular infiltration was detected in the labyrinth in one placenta from a $\mathrm{NaAsO}_{2}$ exposed female (Figure 1(f)).

To analyze the differences in placental histological findings among groups, the percentages obtained for each alteration were compared. As shown in Table 2, a significant increase in infarcts in the junction zone was detected in placentas from $\mathrm{NaAsO}_{2}$ exposed females, as well as vascular congestion in the labyrinth zone.

\subsection{Immunelocalization of GLUT1, GLUT3, and GLUT4 in} Murine Placenta. GLUT1, GLUT3, and GLUT4 were expressed in the labyrinth (Figure 2); in the case of GLUT1, protein expression was identified on both sides of the maternal-fetal interface, mainly in the brush border of the syncytiotrophoblast layer (Figure 2(a)) and weakly in the fetal endothelium. In the case of GLUT3, protein expression was localized mainly in syncytiotrophoblast layer (Figure 2(c)). Finally, GLUT4 expression showed the same pattern as that observed for GLUT1; the protein was expressed on both sides of the maternal-fetal interface (Figure 2(e)). No changes in the localization of GLUT transporters were detected in placentas from females exposed to $\mathrm{NaAsO}_{2}$ (data not shown). The controls for antibody heterologous recognition using rat heart (GLUT1; Figure 2(b) and GLUT4; Figure 2(f)) and rat testis (GLUT3; Figure 2(d)) showed strong signal for each protein.

3.4. Effect of $\mathrm{NaAsO}_{2}$ Exposure on GLUT1, GLUT3, and GLUT4 Expression. To analyze the expression of GLUT transporters among groups, image analysis was performed using the methodology previously reported by our research group [30, 31]. The expression of GLUT1 showed no difference between placentas in female controls and those that were exposed to iAs (Figure 3). Although a nonsignificant increase was detected in GLUT3 expression in placentas from female mice exposed to $12 \mathrm{ppm}$ of $\mathrm{NaAsO}_{2}$, the expression of this transporter was quite similar in placentas from females exposed to $20 \mathrm{ppm}$ and in nonexposed females.

The expression of GLUT4 was significantly lower $(P<$ 0.05 ) in placentas exposed to $12 \mathrm{ppm}$ of $\mathrm{NaAsO}_{2}$ compared with the expression in placentas from control females and those exposed to $20 \mathrm{ppm}$ iAs (Figure 3).

When iAs and its metabolites were quantified in placenta samples (Table 3), higher concentrations of iAs, MAs, and DMAs were found in placentas from exposed females than in those from control mice. The main arsenical species found in placental tissue was DMAs, which agrees with the results reported by Devesa et al. (2006). However, we did not find a significant difference in iAs or in arsenical species concentrations relative to the dose used for iAs exposure. This may be, in part, due to significantly lower water consumption by mice in the $20 \mathrm{ppm}$ as compared to the $12 \mathrm{ppm}$ group. Similar results were observed in Paul et al. 2007 where control mice consumed an average of $5.0 \mathrm{~mL}$ of water per day $(\mathrm{mL} / \mathrm{d})$. Mice in the $25 \mathrm{ppm}$ and $50 \mathrm{ppm}$ group consumed significantly less water: $3.8 \mathrm{~mL}$ and $2.5 \mathrm{~mL}$ per day, respectively [33].

\section{Discussion}

In the present study, we used an environmentally relevant concentration of $\mathrm{NaAsO}_{2}$. It is recognized that mice metabolize iAs and clear iAs metabolites from tissues more efficiently than humans and that significantly higher exposure levels or longer exposure times are needed in mice to produce symptoms of chronic As toxicity found in humans [33]. Prenatal exposure to $\mathrm{NaAsO}_{2}$ in $\mathrm{Balb} / \mathrm{c}$ strain mice can cause maternal toxicity, which presents as a decrease in body weight of exposed females relative to nonexposed mice [34]. In our study, no maternal toxicity was detected as maternal weight showed no significant difference from the nonexposed group. Although the existing studies are highly diverse, a nonsignificant decrease in body weight in mice exposed to iAs has been reported by another groups [24, 35, 36]. As a result of prenatal exposure, fetuses from exposed litters showed lower body weights compared with fetuses from nonexposed litters, and although fetuses from exposed females were not measured, some of them were smaller than those from nonexposed litters (data not shown). In addition, decrease in placental weight in As exposed females could be due to an impairment in placental vasculogenesis [36], reduction of cytotrophoblastic plugging, and syncytium formation caused by oxidative stress which could generate placental 


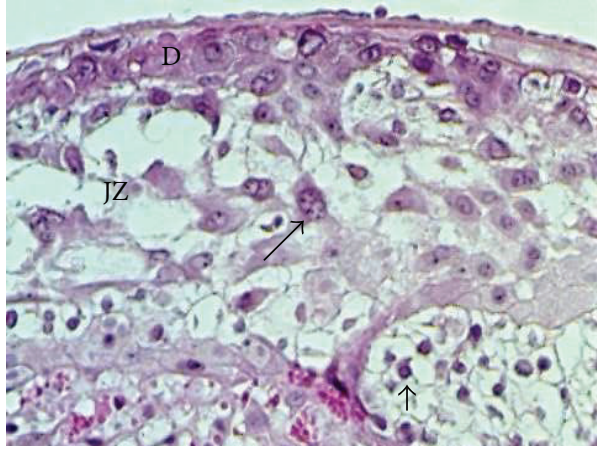

(a)

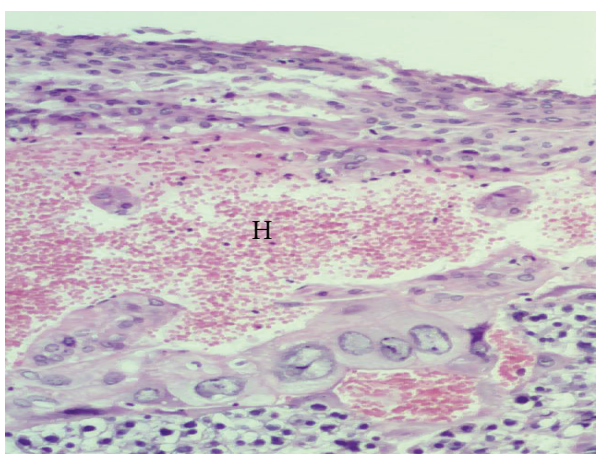

(c)

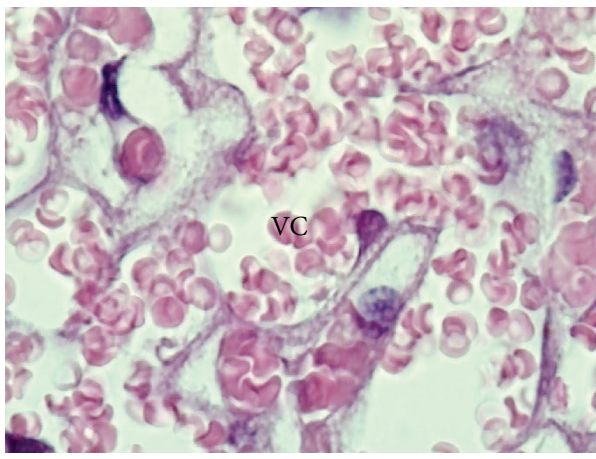

(e)

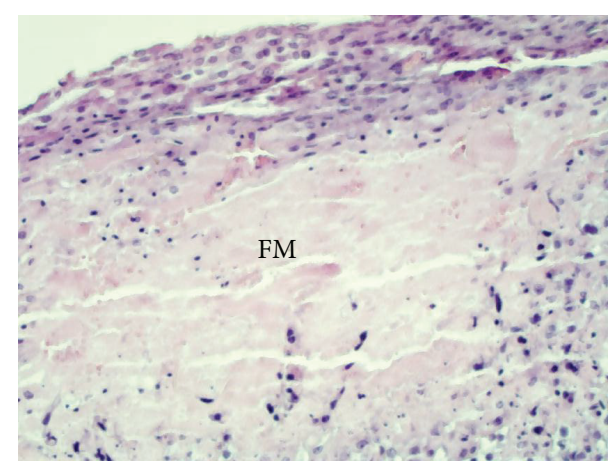

(b)

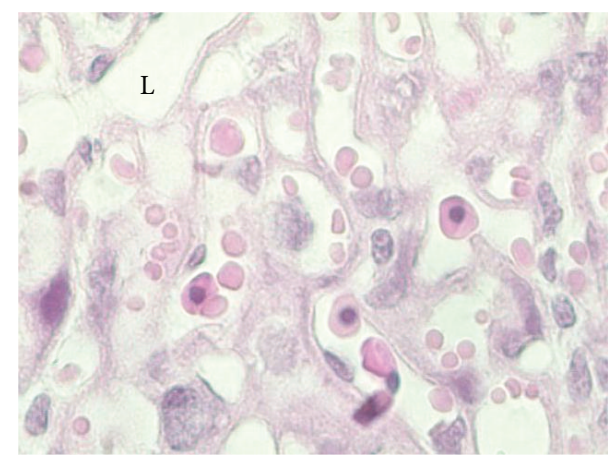

(d)

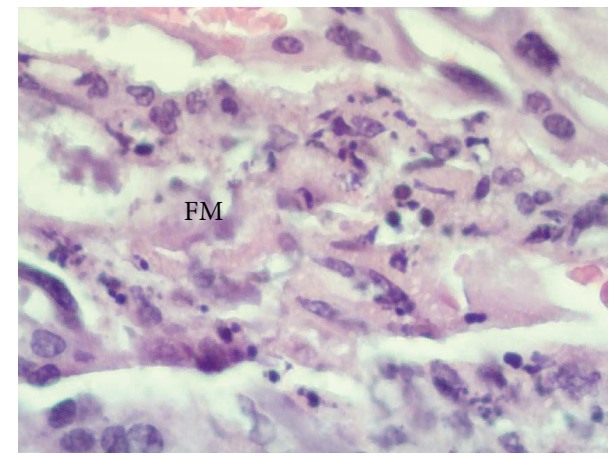

(f)

Figure 1: Morphologic alterations found in placentas from female mice exposed to $\mathrm{NaAsO}_{2}$ in water. Microphotographs show the decidua (D), junction zone (JZ), and labyrinth (L) zones of murine placenta. (a) Normal morphology of murine placenta and the trophoblast giant cells (arrows) and clusters of glycogen trophoblast cells (arrowheads) are shown in JZ and near to L. Magnification 10x. (b) Infarct and deposits of fibrinoid material (FM) present in JZ and L. (c) Hemorrhagic lesion located in D zone found in placenta from a $\mathrm{NaAsO}_{2}$ exposed female. Magnification 10x. (d) Normal appearance of the L zone present in placenta from a nonexposed female. Magnification 60x. (e) Vascular congestion (VC) located in $\mathrm{L}$ zone present in the placenta from a $\mathrm{NaAsO}_{2}$ exposed female. Magnification 60x. (f) Magnification of fibrinoid material (FM) in the placenta from a female exposed to $\mathrm{NaAsO}_{2}$. Magnification 60x. H\&E stain.

pathology and/or preeclampsia [37-39]. These results suggest that arsenic exposure may induce placental tissue damage and compromise the supply of nutrients, oxygen, hormones, and other growth factors that are necessary for fetal welfare.

The histopathological study revealed morphological changes in placental tissue such as fibrosis, hemorrhage, infarcts, and vascular congestion. These results are consistent with those reported by Levario-Carrillo et al. (2004), who evaluated the effect of methyl parathion, an organophosphate pesticide, on placental morphology in pregnant rats and reported large areas of fibrosis and hemorrhage in decidua basalis as a consequence of exposure. The authors suggested that congestion detected in the labyrinth might act as a compensatory mechanism to dilute the toxic agent and replace the dead cells [40]. However, vascular congestion could be related with deficiencies in vasculogenesis as was reported by Paul et al. [35]. The presence of fibrosis in the junction zone has been suggested as a normal indicator of placental aging [41], and the fibrinoid material found in placentas with infarct lesions suggests a remodeling mechanism to replace 


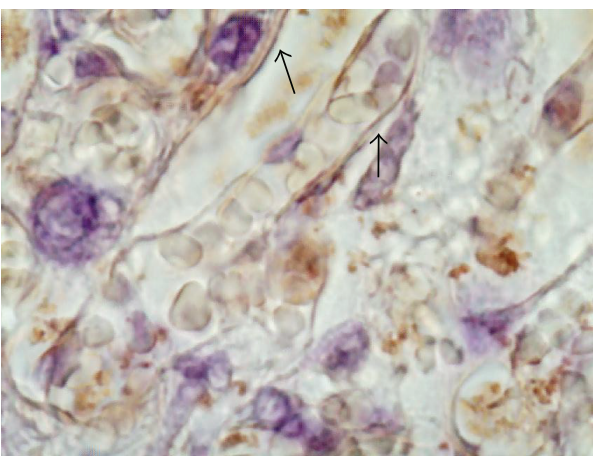

(a)

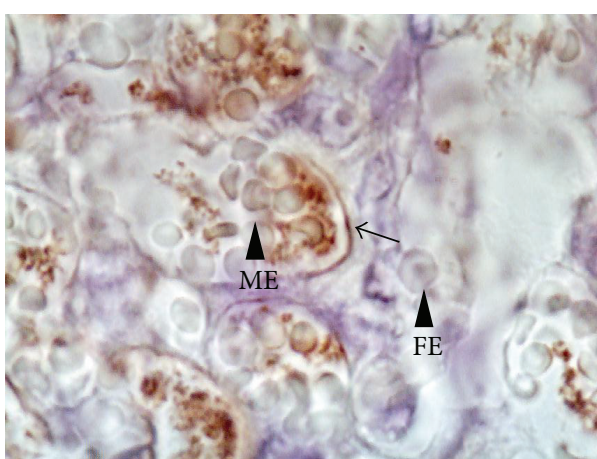

(c)

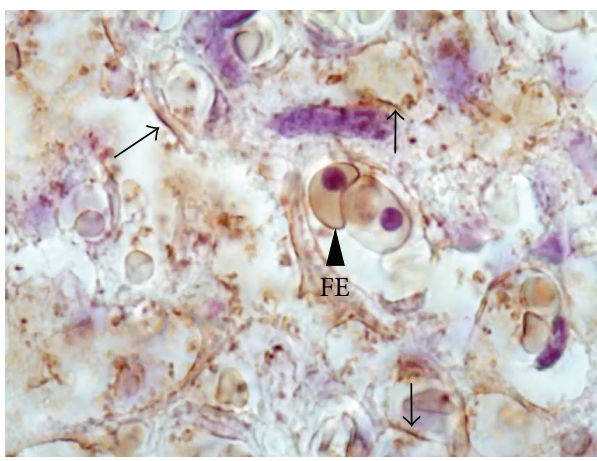

(e)

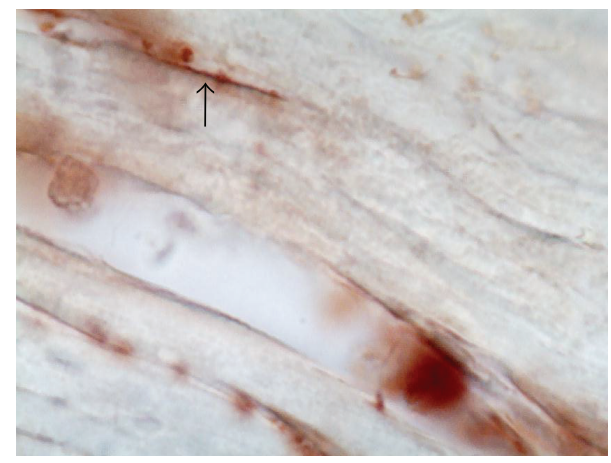

(b)

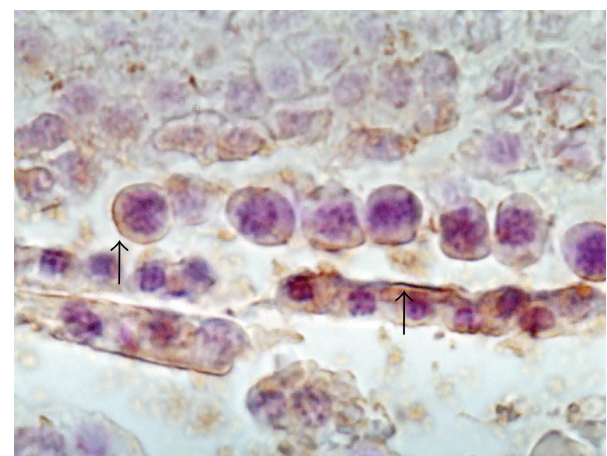

(d)

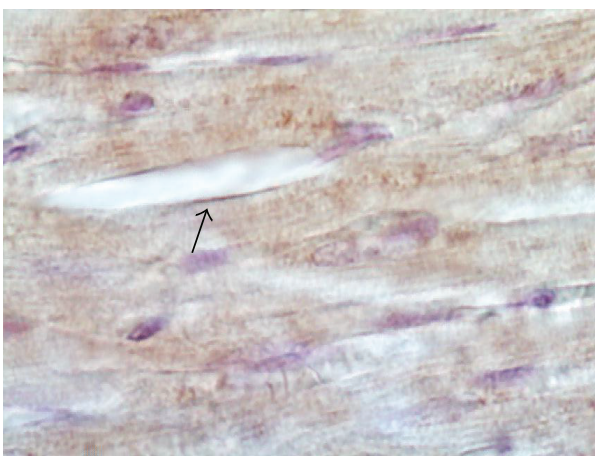

(f)

FigURE 2: Immunelocalization of glucose transporters in placenta of female mice. The photomicrographs represent immunelocalization of GLUT transporters in placenta from nonexposed females. Samples were counterstained with hematoxylin after an immunohistochemical procedure. (a), (c), and (e) show a positive signal for GLUT1, 3, and 4, respectively, (arrows) in mouse placenta. GLUT1 was identified on both sides of the maternal-fetal interface while GLUT3 was localized mainly in the fetal endothelium. GLUT4 was detected in both syncytiotrophoblast and stromal cells. Positive controls were mounted in rat tissues: (b) heart for GLUT1; (d) testis for GLUT3; and (f) heart for GLUT4. The signal for GLUT1 and GLUT4 was localized on myocytes sarcoplasm and GLUT3 in cytosol of Sertoli cells. ME: maternal erythrocyte; FE: fetal erythrocyte. Magnification 60x.

the damaged tissue. Considering these findings, we suggest the existence of a general mechanism whereby the placenta responds to aggression regardless of the toxic agent (arsenic, lead, methyl parathion, etc.). In addition, histological alterations found in placentas from exposed females were not severe enough to explain the diminution in placental and fetal weight, which underscores the need to analyze these changes at the molecular level.

The placental expression of GLUT1, GLUT3, and GLUT4 has been reported previously $[15,42]$, and our findings are consistent with these results. GLUT1 is a ubiquitous isoform expressed in almost all of the tissues examined [18]. The GLUT1 transporter was located in both the junction zone and the labyrinth. Expression in the junction zone could be necessary to satisfy the metabolic demands of the placenta, whereas its expression in the labyrinth could be involved in the maternal-fetal transfer of glucose [42]. The specific expression of GLUT3 in the labyrinth suggests that this transporter is more important for the regulation of glucose transport than GLUT1. GLUT4 expression was localized by 
TABLE 3: Concentration and relative proportion of iAs and methylated species in placental tissue according to $\mathrm{NaAsO}_{2}$ concentration.

\begin{tabular}{|c|c|c|c|c|c|c|}
\hline \multirow{3}{*}{ Arsenical } & \multicolumn{6}{|c|}{ Arsenite concentration in drinking water (ppm) } \\
\hline & \multicolumn{2}{|c|}{0} & \multicolumn{2}{|c|}{12} & \multicolumn{2}{|c|}{20} \\
\hline & ng As/g of tissue ${ }^{a}$ & $\%$ & ng As/g of tissue ${ }^{a}$ & $\%$ & ng As/g of tissue ${ }^{a}$ & $\%$ \\
\hline iAs & $1.85 \pm 0.05$ & 100 & $7.425 \pm 3.31$ & 21 & $8.573 \pm 4.23$ & 25 \\
\hline MAs & UD & 0 & $1.945 \pm 0.54$ & 6 & $1.592 \pm 0.49$ & 5 \\
\hline DMAs & UD & 0 & $25.55 \pm 3.87$ & 73 & $24.21 \pm 4.84$ & 70 \\
\hline tAs & $1.85 \pm 0.05$ & 100 & $34.92 \pm 5.56^{*}$ & 100 & $34.38 \pm 8.69^{*}$ & 100 \\
\hline
\end{tabular}

${ }^{\mathrm{a}}$ mean \pm s.d.; $\%$ of arsenical species in relation to total arsenic (tAs).

UD: undetected concentration.

* Difference between exposed versus control group; $P<0.01$, one way ANOVA test.

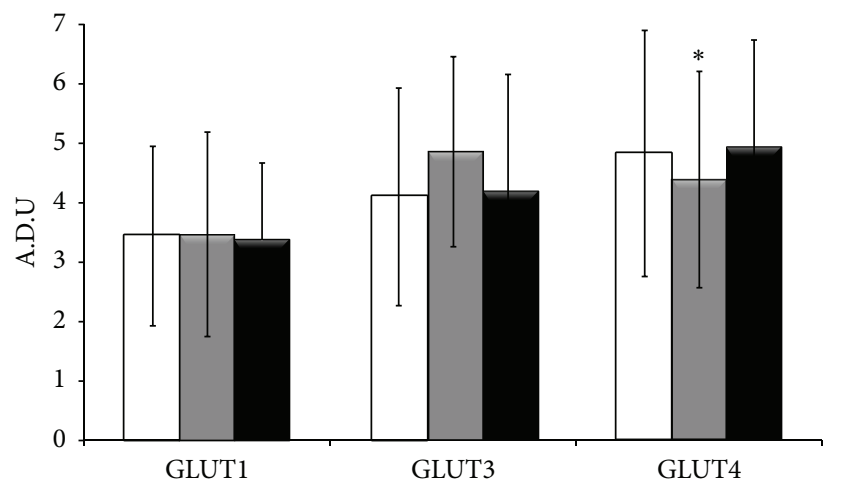

Figure 3: Expression of GLUT1, 3, and 4 in placenta from female mice exposed during gestation to $\mathrm{NaAsO}_{2}$ through water. Each bar indicates the mean \pm s.d. of arbitrary units of optical density (ADU) obtained for each transporter ( $n=300$ for each protein), according to $\mathrm{NaAsO}_{2}$ water concentration: White, 0 ppm; Gray, $12 \mathrm{ppm}$; and Black, $20 \mathrm{ppm}$. Comparisons among groups were performed using the Wilcoxon range test; ${ }^{*} P<0.05$.

Xing et al. (1998) in the stromal cells of human and rodent term placentas using indirect IHC [15]. Nevertheless, we identified the expression in both syncytiotrophoblast and stromal cells. GLUT4 is already synthesized and maintained in subplasmalemmal vesicles. It is primarily responsible for the rapid upregulation of transport activity observed in some tissues (fat and muscle) in response to insulin, which is supplemented by a slower phase of transcription and translation [18]. In the placenta, the syncytial GLUT4 could help improve glucose transport in response to any insulin stimulus (maternal or fetal).

Instead, we observed an increase in the expression of GLUT3 in placentas exposed to $12 \mathrm{ppm}$ of $\mathrm{NaAsO}_{2}$ (although the difference was not statistically significant). These results are consistent with those reported by Boileau et al. (1995), who analyzed the expression of GLUT1 and GLUT3 in placentas from diabetic rats and demonstrated an increase in GLUT3 expression, whereas the expression of GLUT1 remained unchanged [43]. Considering this evidence, we suggest that exposure to $\mathrm{NaAsO}_{2}$ induces a state of maternal hyperglycemia in which GLUT3 seems to be more sensitive than GLUT1 to blood glucose levels. Additionally, the expression of the placental GLUT4 transporter was decreased in the group exposed to $12 \mathrm{ppm}$. Decrease of GLUT4 is related to a mechanism to protect the fetus from high levels of maternal glucose [44]. Although we did not determine glucose concentrations in the blood of females during As exposure, hyperglycemia, high levels of insulin, and impaired glucose tolerance in pregnant mice exposed to As have been reported $[24,35]$. Alterations in the transfer of glucose are common in many abnormalities of fetal growth (fetal macrosomia and intrauterine growth restriction), and this relationship could explain the adverse pregnancy outcomes associated with iAs exposure. However, in the group exposed to $20 \mathrm{ppm}$ this regulation does not seem to occur because expression did not differ from the control group. These differences are most likely related to the fact that females exposed to this concentration consumed a lower volume of water, as was previously described by Paul et al. [35].

On the other hand, studies performed in a $S$. cerevisiae model have demonstrated that GLUT1 and GLUT4 participate in the uptake of arsenite and MAs, by a different pathway used for glucose, which might contribute to As toxicity [4547]. In addition, some studies show that glucose uptake can be inhibited by As, even with high levels of insulin [46, 48], these findings suggest that iAs exposure during pregnancy could impair placental capacity for nutrient transfer resulting in pregnancy complications and/or restricted fetal growth [17].

To our knowledge, this is the first report concerning the expression of GLUT4 in placentas from mice exposed to low levels of $\mathrm{NaAsO}_{2}$, and our findings are consistent with the mechanism proposed by Paul et al. (2007) to explain the diabetogenic potential of As. Paul et al. (2007) suggest that arsenical trivalent species disrupt the activity of (3-phosphoinositide-dependent) kinases 1 and 2, blocking the intracellular signaling cascade triggered by the insulin receptor and resulting in the blockage of GLUT4 translocation from endosomal vesicles to the plasma membrane, which consequently decreases GLUT4 expression in cells [35]. In our study, the decrease in GLUT4 expression in placentas might explain the low fetal weight observed in the exposed groups. However, more research is required to analyze whether the signaling mechanism of GLUT4 is similar to that reported in adipocyte or muscle cells.

These results are important as they provide evidence that, in pregnant women, even low concentrations of iAs in water may damage the placenta and the fetus, not only affecting its 
survival in utero but also modifying the expression of its genes and increasing the risk of disease in the future.

$\begin{array}{ll}\text { Abbreviations } \\ \text { As: } & \text { Arsenic } \\ \text { DMAs: } & \text { Dimethyl arsenic } \\ \text { GLUT: } & \text { Glucose transporter } \\ \text { (HG-CT-AAS): } & \begin{array}{l}\text { Hydride generation-cryotrapping-atomic } \\ \text { absorption spectrometry }\end{array} \\ & \text { Inorganic arsenic } \\ \text { IHs: } & \text { Immunohistochemical analysis } \\ \text { MAs: } & \text { Methyl arsenic } \\ \text { NaAsO } & \text { Sodium arsenite } \\ \text { tAs: } & \text { Total arsenic. }\end{array}$

\section{Conflict of Interests}

The authors have no other relevant affiliations or financial involvement with any organization or entity with a financial interest in or financial conflict with the subject matter or materials discussed in the paper apart from those disclosed.

\section{Acknowledgments}

This work was partially supported by the Mixed Fund of the Government of the State of Chihuahua (FOMIX) and the National Council of Science and Technology (CONACyT) (CHIH-2008-C01-92074). Daniela Sarahí Gutiérrez-Torres was the recipient of an M.Sc. scholarship from CONACyT (Register no. 213781).

\section{References}

[1] A. H. Smith, C. Hopenhayn-Rich, M. N. Bates et al., "Cancer risks from arsenic in drinking water," Environmental Health Perspectives, vol. 97, pp. 259-267, 1992.

[2] A. Hernández-Zavala, L. M. Del Razo, C. Aguilar, G. G. GarcíaVargas, V. H. Borja, and M. E. Cebrián, "Alteration in bilirubin excretion in individuals chronically exposed to arsenic in Mexico," Toxicology Letters, vol. 99, no. 2, pp. 79-84, 1998.

[3] M. Rahman, M. Tondel, S. A. Ahmad, I. A. Chowdhury, M. H. Faruquee, and O. Axelson, "Hypertension and arsenic exposure in Bangladesh," Hypertension, vol. 33, no. 1, pp. 74-78, 1999.

[4] D. N. Guha Mazumder, R. Haque, N. Ghosh et al., "Arsenic levels in drinking water and the prevalence of skin lesions in West Bengal, India," International Journal of Epidemiology, vol. 27, no. 5, pp. 871-877, 1998.

[5] V. M. Rodríguez, M. E. Jiménez-Capdeville, and M. Giordano, "The effects of arsenic exposure on the nervous system," Toxicology Letters, vol. 145, no. 1, pp. 1-18, 2003.

[6] M. P. Waalkes, J. M. Ward, and B. A. Diwan, "Induction of tumors of the liver, lung ovary and adrenal in adult mice after brief maternal gestational exposure to inorganic arsenic: promotional effects of postnatal phorbol ester exposure on hepatic and pulmonary, but not dermal cancers," Carcinogenesis, vol. 25, no. 1, pp. 133-141, 2004.

[7] P. Ravenscroft, H. Brammer, and K. Richards, Arsenic Pollution: A Global Synthesis, John Wiley \& Sons, West Sussex, UK, 2009.
[8] ATSDR, Toxicological Profile for Arsenic, Division of Toxicology, Agency for Toxic Substances and Disease Registry, Atlanta, Ga, USA, 2007.

[9] S. A. Ahmad, M. H. Salim Ullah Sayed, S. Barua et al., "Arsenic in drinking water and pregnancy outcomes," Environmental Health Perspectives, vol. 109, no. 6, pp. 629-631, 2001.

[10] M. J. Leroy, G. Tanguy, M. Vial, W. Rostene, A. Malassine, and F. Ferré, "The effect of vasoactive intestinal peptide (VIP) on the contractile activity of human uterine smooth muscle," Clinical and Experimental Pharmacology and Physiology, vol. 18, no. 4, pp. 205-215, 1991.

[11] K. K. Saha, A. Engström, J. D. Hamadani, F. Tofail, K. M. Rasmussen, and M. Vahter, "Pre- and postnatal arsenic exposure and body size to 2 years of age: a cohort study in rural Bangladesh," Environmental Health Perspectives, vol. 120, no. 8, pp. 1208-1214, 2012.

[12] H. Guan, F. Piao, X. Zhang et al., "Prenatal exposure to arsenic and its effects on fetal development in the general population of dalian," Biological Trace Element Research, vol. 149, no. 1, pp. 10-15, 2012.

[13] P. Georgiades, A. C. Fergyson-Smith, and G. J. Burton, “Comparative developmental anatomy of the murine and human definitive placentae," Placenta, vol. 23, no. 1, pp. 3-19, 2002.

[14] A. Malassiné, J.-L. Frendo, and D. Evain-Brion, "A comparison of placental development and endocrine functions between the human and mouse model," Human Reproduction Update, vol. 9, no. 6, pp. 531-539, 2003.

[15] A. Y. Xing, J. C. Challier, J. Lepercq et al., "Unexpected expression of glucose transporter 4 in villous stromal cells of human placenta," The Journal of Clinical Endocrinology and Metabolism, vol. 83, no. 11, pp. 4097-4101, 1998.

[16] G. T. Knipp, K. L. Audus, and M. J. Soares, "Nutrient transport across the placenta," Advanced Drug Delivery Reviews, vol. 38, no. 1, pp. 41-58, 1999.

[17] T. Jansson and T. L. Powell, "Human placental transport in altered fetal growth: Does the placenta function as a nutrient sensor? A review," Placenta, vol. 27, pp. 91-97, 2006.

[18] N. P. Illsley, "Glucose transporters in the human placenta," Placenta, vol. 21, no. 1, pp. 14-22, 2000.

[19] S. Lager and T. L. Powell, "Regulation of nutrient transport across the placenta," Journal of Pregnancy, vol. 2012, Article ID 179827, 14 pages, 2012.

[20] G. Concha, G. Vogler, D. Lezcano, B. Nermell, and M. Vahter, "Exposure to inorganic arsenic metabolites during early human development," Toxicological Sciences, vol. 44, no. 2, pp. 185-190, 1998.

[21] J. C. States, A. V. Singh, T. B. Knudsen et al., "Prenatal arsenic exposure alters gene expression in the adult liver to a proinflammatory state contributing to accelerated atherosclerosis," PLoS ONE, vol. 7, no. 6, Article ID e38713, 2012.

[22] M. E. Dávila-Esqueda, J. M. Morales, M. E. Jiménez-Capdeville et al., "Low-level subchronic arsenic exposure from prenatal developmental stages to adult life results in an impaired glucose homeostasis," Experimental and Clinical Endocrinology and Diabetes, vol. 119, no. 10, pp. 613-617, 2011.

[23] S. F. Farzan, M. R. Karagas, and Y. Chen, "In utero and early life arsenic exposure in relation to long-term health and disease," Toxicology and Applied Pharmacology, vol. 272, no. 2, pp. 384390, 2013.

[24] D. S. Hill, B. J. Wlodarczyk, L. E. Mitchell, and R. H. Finnell, "Arsenate-induced maternal glucose intolerance and neural 
tube defects in a mouse model," Toxicology and Applied Pharmacology, vol. 239, no. 1, pp. 29-36, 2009.

[25] A. Díaz-Villaseñor, M. C. Sánchez-Soto, M. E. Cebrián, P. Ostrosky-Wegman, and M. Hiriart, "Sodium arsenite impairs insulin secretion and transcription in pancreatic $\beta$-cells," Toxicology and Applied Pharmacology, vol. 214, no. 1, pp. 30-34, 2006.

[26] F. S. Walton, A. W. Harmon, D. S. Paul, Z. Drobná, Y. M. Patel, and M. Styblo, "Inhibition of insulin-dependent glucose uptake by trivalent arsenicals: possible mechanism of arsenic-induced diabetes," Toxicology and Applied Pharmacology, vol. 198, no. 3, pp. 424-433, 2004.

[27] L. M. Del Razo, M. Stýblo, W. R. Cullen, and D. J. Thomas, "Determination of trivalent methylated arsenicals in biological matrices," Toxicology and Applied Pharmacology, vol. 174, no. 3, pp. 282-293, 2001.

[28] Normalización, "Especificaciones técnicas para la producción, cuidado y uso de los animales de laboratorio," Tech. Rep. NOM062-ZOO-1999, Normalización, 2001.

[29] D. M. Opresko, B. E. Sample, and G. W. Suter, Toxicological Benchmarks to Wildlife, edited by Division PbtRAPHSR, U.S. Department of Energy, Oak Ridge, Tenn, USA, 1996.

[30] B. González-García, M. E. Olave, E. Ramos-Martínez, C. González-Horta, M. Levario-Carrillo, and B. Sánchez-Ramírez, "Decrease of muscarinic cholinergic receptors expression in placenta from rats exposed to methyl parathion," Human \& Experimental Toxicology, vol. 27, no. 3, pp. 241-246, 2008.

[31] E. González-Puebla, C. González-Horta, R. Infante-Ramírez, L. H. Sanin, M. Levario-Carrillo, and B. Sánchez-Ramírez, "Altered expressions of MMP-2, MMP-9, and TIMP-2 in placentas from women exposed to lead," Human \& Experimental Toxicology, vol. 31, no. 7, pp. 662-670, 2012.

[32] V. Devesa, B. M. Adair, J. Liu et al., "Arsenicals in maternal and fetal mouse tissues after gestational exposure to arsenite," Toxicology, vol. 224, no. 1-2, pp. 147-155, 2006.

[33] D. S. Paul, A. Hernández-Zavala, F. S. Walton et al., "Examination of the effects of arsenic on glucose homeostasis in cell culture and animal studies: development of a mouse model for arsenic-induced diabetes," Toxicology and Applied Pharmacology, vol. 222, no. 3, pp. 305-314, 2007.

[34] A. Wang, S. D. Holladay, D. C. Wolf, S. A. Ahmed, and J. L. Robertson, "Reproductive and developmental toxicity of arsenic in rodents: a review," International Journal of Toxicology, vol. 25, no. 5, pp. 319-331, 2006.

[35] D. S. Paul, A. W. Harmon, V. Devesa, D. J. Thomas, and M. Stýblo, "Molecular mechanisms of the diabetogenic effects of arsenic: inhibition of insulin signaling by arsenite and methylarsonous acid," Environmental Health Perspectives, vol. 115, no. 5, pp. 734-742, 2007.

[36] W. He, R. J. Greenwell, D. M. Brooks, L. Calderón-Garcidueñas, H. D. Beall, and J. D. Coffin, "Arsenic exposure in pregnant mice disrupts placental vasculogenesis and causes spontaneous abortion," Toxicological Sciences, vol. 99, no. 1, pp. 244-253, 2007.

[37] E. Jauniaux, L. Poston, and G. J. Burton, "Placental-related diseases of pregnancy: involvement of oxidative stress and implications in human evolution," Human Reproduction Update, vol. 12, no. 6, pp. 747-755, 2006.

[38] M. Vahter, "Effects of arsenic on maternal and fetal health," Annual Review of Nutrition, vol. 29, pp. 381-399, 2009.
[39] S. Ahmed, S. M.-E. Khoda, R. S. Rekha et al., "Arsenicassociated oxidative stress, inflammation, and immune disruption in human placenta and cord blood," Environmental Health Perspectives, vol. 119, no. 2, pp. 258-264, 2011.

[40] M. Levario-Carrillo, M. E. Olave, D. C. Corral, J. G. Alderete, S. M. Gagioti, and E. Bevilacqua, "Placental morphology of rats prenatally exposed to methyl parathion," Experimental and Toxicologic Pathology, vol. 55, no. 6, pp. 489-496, 2004.

[41] E. P. C. T. De Rijk, E. Van Esch, and G. Flik, "Pregnancy dating in the rat: placental morphology and maternal blood parameters," Toxicologic Pathology, vol. 30, no. 2, pp. 271-282, 2002.

[42] B.-C. Shin, K. Fujikura, T. Suzuki, S. Tanaka, and K. Takata, "Glucose transporter GLUT3 in the rat placental barrier: a possible machinery for the transplacental transfer of glucose," Endocrinology, vol. 138, no. 9, pp. 3997-4004, 1997.

[43] P. Boileau, C. Mrejen, J. Girard, and S. Hauguel-de Mouzon, "Overexpression of GLUT3 placental glucose transporter in diabetic rats," Journal of Clinical Investigation, vol. 96, no. 1, pp. 309-317, 1995.

[44] T. Hahn, S. Barth, U. Weiss, W. Mosgoeller, and G. Desoye, "Sustained hyperglycemia in vitro down-regulates the GLUT1 glucose transport system of cultured human term placental trophoblast: a mechanism to protect fetal development?" The FASEB Journal, vol. 12, no. 12, pp. 1221-1231, 1998.

[45] Z. Liu, E. Boles, and B. P. Rosen, "Arsenic trioxide uptake by hexose permeases in Saccharomyces cerevisiae," The Journal of Biological Chemistry, vol. 279, no. 17, pp. 17312-17318, 2004.

[46] Z. Liu, M. A. Sanchez, X. Jiang, E. Boles, S. M. Landfear, and B. P. Rosen, "Mammalian glucose permease GLUT1 facilitates transport of arsenic trioxide and methylarsonous acid," Biochemical and Biophysical Research Communications, vol. 351, no. 2, pp. 424-430, 2006.

[47] X. Jiang, J. R. McDermott, A. Abdul Ajees, B. P. Rosena, and Z. Liu, "Trivalent arsenicals and glucose use different translocation pathways in mammalian GLUT1," Metallomics, vol. 2, no. 3, pp. 211-219, 2010.

[48] M. Bazuine, D. M. Ouwens, D. S. Gomes De Mesquita, and J. A. Maassen, "Arsenite stimulated glucose transport in 3T3-L1 adipocytes involves both Glut4 translocation and p38 MAPK activity," European Journal of Biochemistry, vol. 270, no. 19, pp. 3891-3903, 2003. 

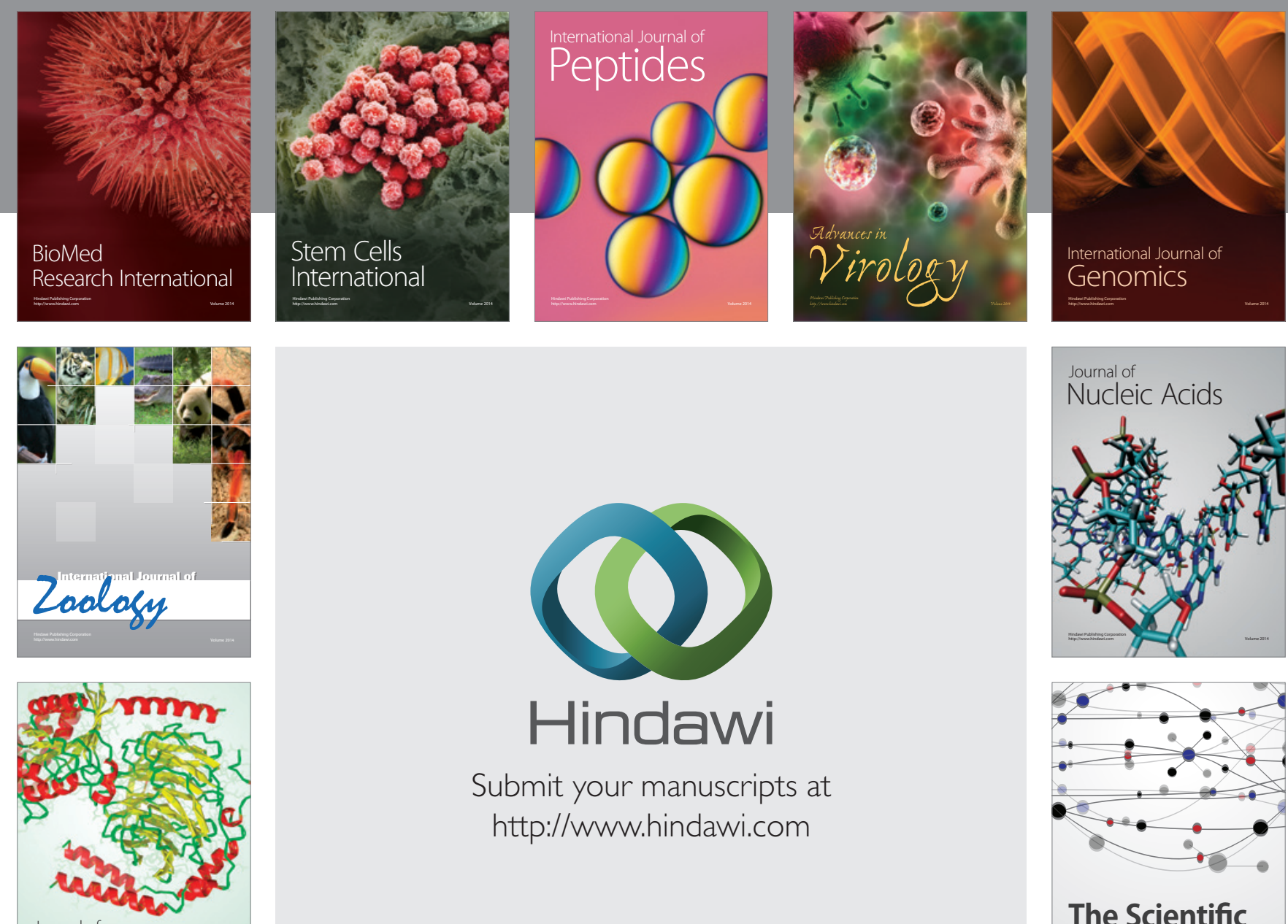

Submit your manuscripts at

http://www.hindawi.com

Journal of
Signal Transduction
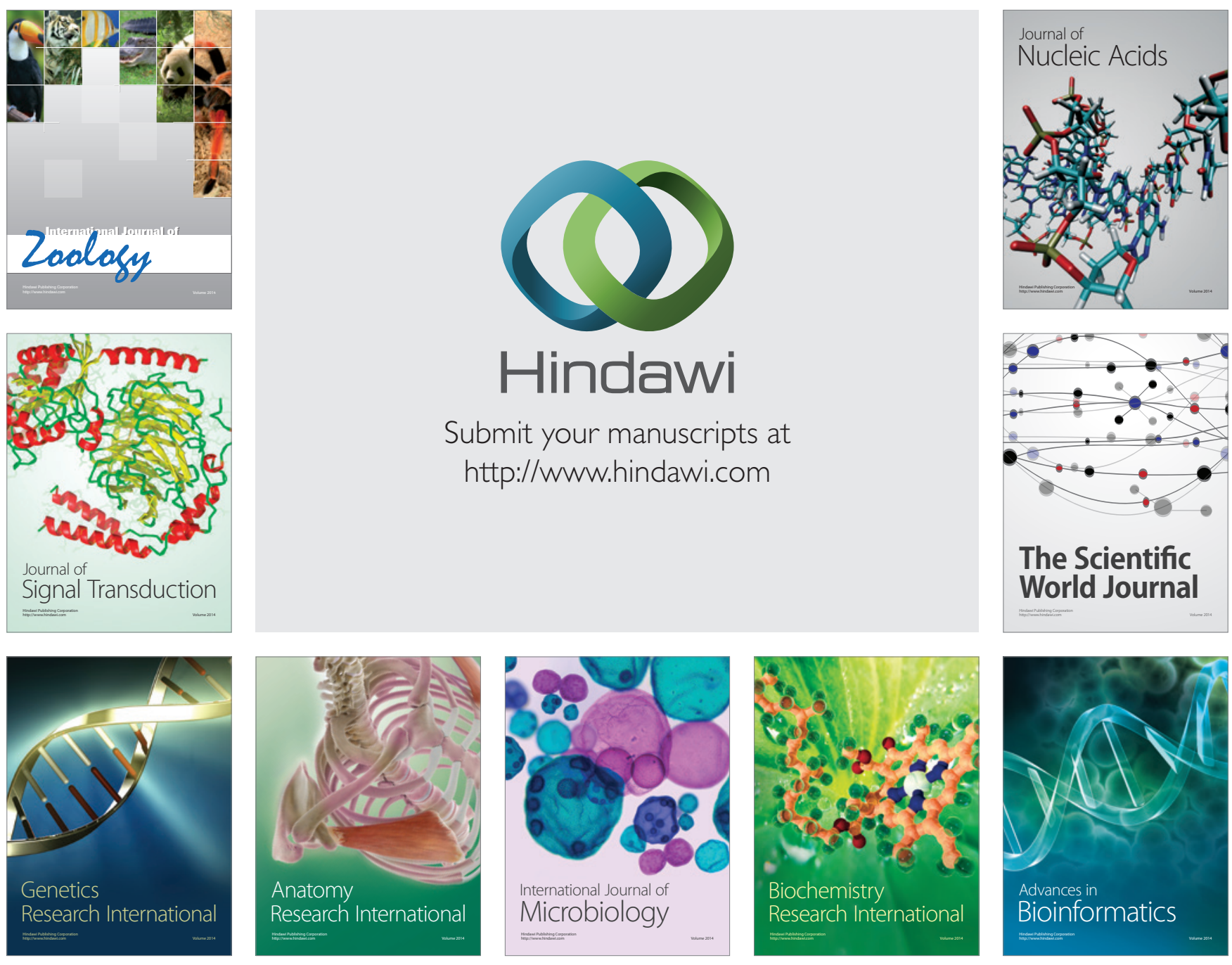

The Scientific World Journal
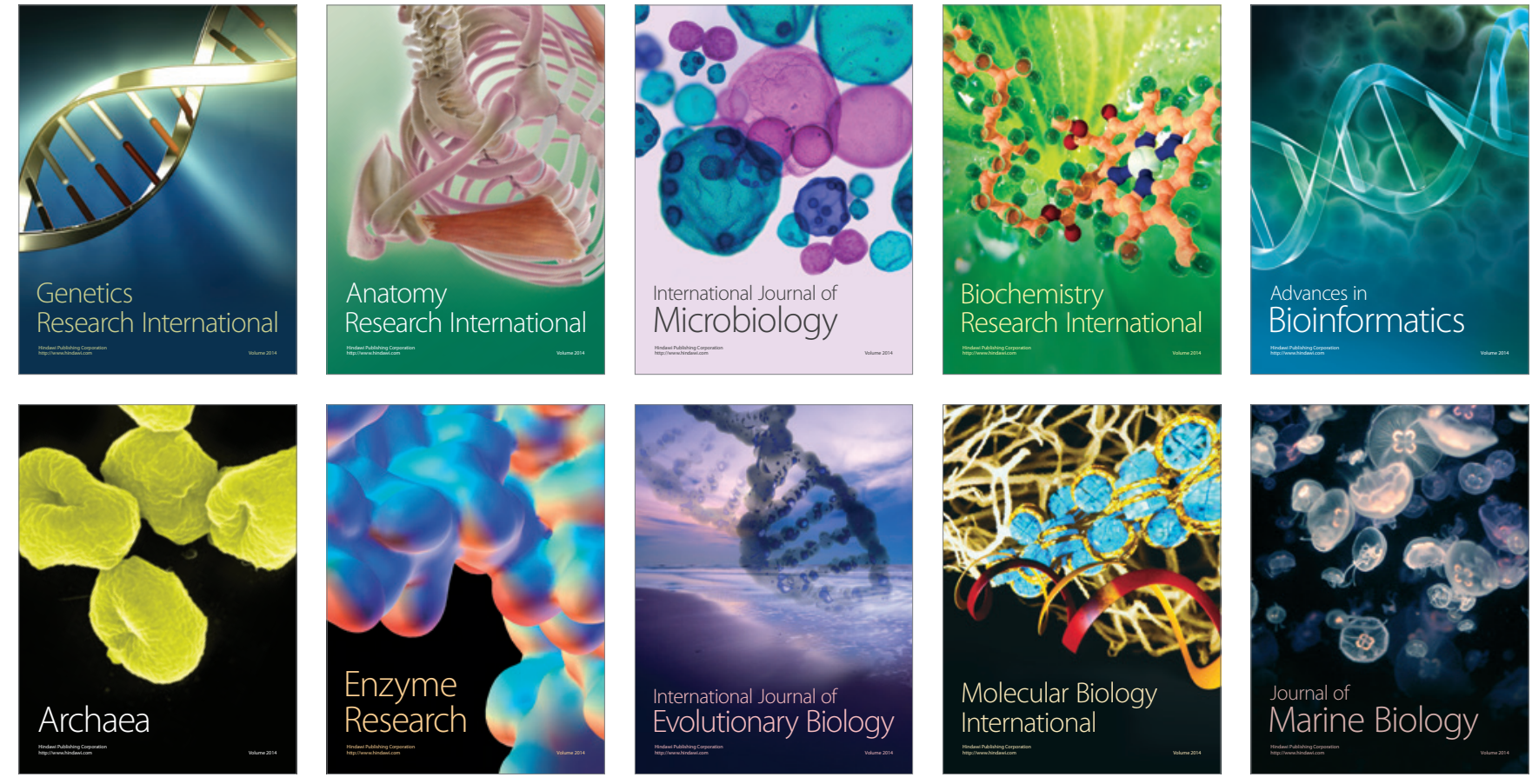